\title{
Balanço hídrico e excreção renal de metabólitos em ovinos alimentados com palma forrageira (Nopalea cochenillifera Salm Dyck) ${ }^{1}$
}

\author{
João P. Neto², Pierre C. Soares ${ }^{2 *}$, Ângela Maria V. Batista ${ }^{3}$, Solano F.J. Andrade , \\ Rafael P.X. Andrade ${ }^{3}$, Rodrigo B. Lucena ${ }^{3}$ e Adriana Guim ${ }^{3}$
}

\begin{abstract}
Neto J.P., Soares P.C., Batisa A.M.V., Andrade S.F.J., Andrade R.P.X., Lucena R.B. \& Guim A. 2016. [Water balance and renal excretion of metabolites in sheep fed forage cactus (Nopalea cochenillifera Salm Dyck).] Balanço hídrico e excreção renal de metabólitos em ovinos alimentados com palma forrageira (Nopalea cochenillifera Salm Dyck). Pesquisa Veterinária Brasileira 36(4):322-328. Departamento de Medicina Veterinária, Universidade Federal Rural de Pernambuco, Rua Dom Manoel de Medeiros s/n, Recife, PE 52171-900, Brazil. E-Mail: pcastro.pe@gmail.com

This study aimed to assess fluid balance and renal excretion of metabolites in lambs without defined breed standard, fed different forage cactus (Nopalea cochenillifera Salm Dyck), in natura and bran. 20 lambs were used, with initial body weight of $20 \mathrm{~kg}$ and were distributed in a completely randomized design, with five treatments and four repetitions. The experimental diets consisted of a control diet based on Bermuda grass hay, soybean meal, limestone and mineral supplement, other treatments aimed at testing different levels of cactus pear plus urea in two forms: fresh and mash and two levels of substitution (50 and 100\%) of dry matter of hay. Blood and urine samples were collected for determination of different metabolites and minerals and use of equations to determine the rates of urinary excretion of these metabolites, rate of endogenous creatinine clearance and electrolyte reabsorption of free water, in addition to recording of water intake and urine volume. The voluntary water intake was influenced by the diets, and the animals subjected to diets containing soybean meal and hay palm and cactus meal were higher than other treatments. Water intake via food was also influenced by diet, being higher in animals fed palm fresh and bran over palm in nature. With respect to total water intake was greater for cows fed diets containing palm in nature compared to the other treatments. The experimental diets influenced the renal excretion of purine metabolites and minerals derived, without changing renal function. The presence of cactus pear both as bran as in nature provides increased urine volume without changing renal function, and to be considered as an excellent food strategy in semiarid.
\end{abstract}

INDEX TERMS: Cactaceous, Nopalea cochenillifera, biochemistry, mineral, renal function, water intake, sheep.

RESUMO.- Objetivou-se avaliar balanço hídrico e excreção renal de metabólitos em borregos sem raça definida, alimentados com diferentes quantidades de palma forragei-

\footnotetext{
${ }^{1}$ Recebido em 24 de abril de 2015.

Aceito para publicação em 18 de janeiro de 2016.

${ }^{2}$ Departamento de Medicina Veterinária, Universidade Federal Rural de Pernambuco (UFRPE), Rua Dom Manuel de Medeiros s/n, Bairro Dois Irmãos, Recife, PE 52171-900, Brasil. *Autor para correspondência: pcastro.pe@gmail.com

${ }^{3}$ Departamento de Zootecnia, UFRPE, Rua Dom Manuel de Medeiros s/n, Bairro Dois Irmãos, Recife, PE 52171-900.
}

ra (Nopalea cochenillifera Salm Dyck), na forma in natura e em farelo. Foram utilizados 20 borregos, com peso vivo médio inicial de $20 \mathrm{Kg}$ e foram distribuídos no delineamento inteiramente casualizado, sendo cinco tratamentos e quatro repetições. As dietas experimentais consistiram em uma dieta controle à base de feno de tífton, farelo de soja, suplemento mineral e calcário, os demais tratamentos visaram testar níveis diferentes de palma forrageira corrigida com ureia em duas formas: in natura e farelada e em dois níveis de substituição (50 e 100\%) da matéria seca do feno de tífton. Amostras de sangue e urina foram 
coletadas para determinação de diferentes metabólitos e minerais e utilização de equações para obtenção dos índices de excreção urinária destes metabólitos, taxa de depuração endógena de creatinina e reabsorção de água livre de eletrólitos, além do registro de ingestão de água e volume de urina. A ingestão voluntária de água sofreu influência das dietas, sendo que os animais submetidos às dietas contendo farelo de palma e feno e farelo de palma foram superiores aos demais tratamentos. A ingestão de água via alimentos também sofreu influência da dieta, sendo maior nos animais que receberam palma in natura e farelo mais palma in natura. Com relação à ingestão total de água foi maior para os animais alimentados com dietas contendo palma in natura em relação aos demais tratamentos. As dietas experimentais influenciaram na excreção renal de metabólitos derivados purínicos e minerais, sem alterar a função renal. A presença da palma forrageira tanto na condição de farelo como in natura proporciona aumento do volume urinário sem alterar a função renal, além de que deve ser considerado como uma excelente estratégia alimentar no semiárido.

TERMOS DE INDEXAÇÃO: Cactácea, Nopalea cochenillifera, palma forrageira, bioquímica, minerais, função renal, ingestão de água, ovinos.

\section{INTRODUÇÃO}

As principais características bromatológicas da palma forrageira (Nopalea cochenillifera) são alto conteúdo de água, minerais, ácidos orgânicos e de carboidratos e baixo teor de proteína. Alta porcentagem de água é uma característica positiva, quando se considera que em regiões áridas e semiáridas existe limitação quantitativa e qualitativa desse nutriente para animais e humanos. Portanto, quando utilizada como forragem, a palma pode reduzir a necessidade do fornecimento de água aos animais, uma vez que bovinos (Lima et al. 2003), caprinos (Vieira et al. 2008a) e ovinos (Bispo et al. 2007) reduzem ou suprimem a ingestão de água quando recebem rações contendo palma forrageira.

0 entendimento dos efeitos do uso da palma forrageira na alimentação de ruminantes sobre o funcionamento renal e sobre o metabolismo do nitrogênio no rúmen e energético é fundamental para otimizar a utilização desse ingrediente em rações, especialmente de animais de interesse pecuário que atenda a demanda nutricional para a região do semi-árido nordestino.

Em sua composição química, a palma forrageira apresenta o conteúdo de matéria mineral elevado. Batista et al. (2003) analisando a composição mineral da palma forrageira, encontraram valores mais elevados de K (50mg/100g de MS), Ca (18-57mg/100g de MS) e Mg (11-17mg/100g de

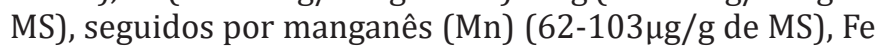

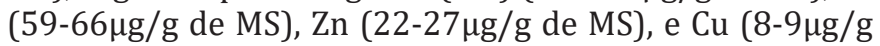
de MS), a variação encontrada na composição mineral da palma é decorrente da espécie, local de cultivo e do estado fisiológico do cladódio. 0 teor de $\mathrm{P}$ presente na palma forrageira é considerado baixo $(0,08-0,16)$ (Germano et al. 1999). De acordo com McDowell (1996) a deficiência de $P$ nas forragens deve ser considerada como um fato importante, uma vez que a falta desse elemento pode determinar efeito negativo sobre o consumo e também sobre a digestibilidade dos nutrientes.

Seus elevados níveis de minerais também podem estar ligados com efeito diurético, já que o balanço na relação dos minerais tem implicações sobre o funcionamento renal e a diurese. De acordo com Szentmihályi et al. (1998), além da água outras substâncias orgânicas (flavonóides, saponinas, vitamina $\mathrm{C}$ ) e alguns minerais como $\mathrm{Mg}$ e $\mathrm{K}$ presentes nas plantas são utilizadas na farmacologia tradicional como diuréticos. Atribui-se o efeito diurético observados em animais alimentados com palma forrageira, as suas altas concentrações de K embora esse mecanismo ainda não seja totalmente conhecido. Segundo Szentmihályi et al. (1998), o K e a relação K: Na são altos na palma.

Embora a palma forrageira tenha sido amplamente estudada nos últimos anos para alimentação animal, ainda sabe-se pouco a respeito do alto percentual desses elementos e de sua real interação e disponibilidade, uma vez que os minerais se inter-relacionam uns com os outros de forma sinérgica ou antagônica. Desta forma tornam-se necessários mais estudos relacionados a esses elementos.

A água é um nutriente importante no metabolismo dos animais e a obtenção de água pode ser via ingestão direta de água ou por meio da dieta (Vieira et al. 2008a). Está comprovado que caprinos alimentados com ração contendo mais de $30 \%$ de palma forrageira in natura podem deixar de ingerir água diretamente no bebedouro (Araújo et al. 2004), e que nestas condições, animais excretam grandes volumes de urina, como mecanismo compensatório na regulação do volume circulante total do corpo (Reece 2004).

Foi observado que a concentração e excreção urinária de sódio $(\mathrm{Na})$ não sofreram interferência da adição de palma na dieta, entretanto, a concentração e a excreção urinária de potássio $(\mathrm{K})$ diminuíram linearmente, embora a ingestão de $\mathrm{K}$ tenha aumentado com a adição de palma na ração (Vieira et al. 2008a). Esses autores verificaram também redução linear nas concentrações plasmática e urinária de uréia e na excreção diária, porém, a taxa de excreção fracionária de uréia aumentou linearmente com a adição de palma forrageira na dieta. Embora esse efeito diurético possa ser devido à alta porcentagem de água, a concentração de $\mathrm{K}$ pode também influir no funcionamento renal, uma vez que o efeito diurético desse mineral é conhecido há muito tempo (Szentmihályi et al. 1998).

Considerando a importância do uso da palma forrageira na dieta de ovinos, faz-se necessário estudar melhor a condição clínica destes animais com ênfase à função renal, permitindo-se verificar se existem danos capazes de interferir nos mecanismos de excreção e reabsorção de nutrientes, os quais podem inferir de modo significativo na saúde animal. Deste modo, objetiva-se avaliar o efeito da adição de palma forrageira, nas condições in natura e farelada, na dieta de ovinos em relação a ingestão de água, volume urinário e excreção renal de metabólitos e minerais.

\section{MATERIAL E MÉTODOS}

Foram utilizados 20 ovinos, adultos, sem padrão racial definido, com peso vivo médio inicial de $18 \mathrm{~kg}$. Antes do início do experimento, foi realizado controle de ecto e endoparasitos. As instala- 
ções consistiram de galpão com cobertura de telha de amianto, dotadas de corredor central e baias individuais medindo $2 \times 1,10 \mathrm{~m}$, providas de comedouro de madeira e bebedouro, piso de cimento e divisórias de madeira.

0 delineamento experimental utilizado foi inteiramente casualizado, com cinco tratamentos e quatro repetições. As dietas experimentais foram compostas por palma forrageira na forma in natura e em farelo de palma (palma desidratada), cultivar miúda (Nopalea cochenillifera Salm Dyck), feno de tifton (Cynodon dactylon), farelo de soja (Glycine max L.), uréia pecuária, calcário e sal mineral. A composição porcentual e valor nutritivo dos ingredientes das dietas experimentais encontram-se no Quadro 1.

0 período experimental teve duração de 75 dias, sendo 15 para adaptação dos animais às instalações e ao manejo. Durante o período de adaptação, todos os animais receberam a dieta base (Feno de tifton - 75,5\%, farelo de soja - 23\%, sal mineral - 0,5\%, calcário - 1,0\%). Na última semana do experimento, procedeu-se avaliação da digestibilidade e do balanço hídrico mediante coleta total de urina por 72 horas. Neste período, foram coletadas amostras de alimentos, água e sobras diariamente. Essas amostras foram identificadas e acondicionadas em freezer a $-20^{\circ} \mathrm{C}$ para posteriores análises. As amostras de alimentos e sobras foram secas em estufa de circulação forçada $\left(55^{\circ} \mathrm{C}\right)$, por 72 horas, e moídas em moinho tipo Wiley, passando por peneiras de $1 \mathrm{~mm}$. Para determinação dos teores de matéria seca (MS), matéria mineral (MM), proteína bruta (PB) e extrato etéreo (EE), foram utilizadas metodologias descritas por Silva \& Queiroz (2002). Para a determinação da fibra em detergente neutro (FDN) foi empregada a metodologia descrita por Van Soest (1991) e os teores de carboidratos não fibrosos (CNF), foram estimados segundo fórmula: $\mathrm{CNF}=100 \%-(\% \mathrm{~PB}+\% \mathrm{FDN}+\% \mathrm{EE}+\% \mathrm{MM}) .0$ consumo voluntário de MS foi calculado mediante a diferença entre as quantidades oferecidas e refugadas.

A palma foi armazenada dentro do galpão de ovinos e diariamente uma parte era utilizada para fornecer in natura para os animais e a outra parte era picada com faca, colocada em cima de uma lona plástica e expostas ao sol durante $24 \mathrm{~h}$. Após este período o material parcialmente desidratado, passava por um triturador de palma e era levado para ser seco em estufa por mais $24 \mathrm{~h} \mathrm{a}$ $60^{\circ} \mathrm{C}$, com ventilação forçada. Após a desidratação o material era triturado em máquina para que o material tivesse granulometria homogênea, facilitando a mistura e estimulando o consumo. Ao final do processo, o farelo de palma forrageira possuía composição química, com base na matéria seca, semelhante ao da palma in natura e MS de 90\%. 0 arraçoamento foi efetuado na forma de dieta completa, as oito e às $15 \mathrm{~h}$, possibilitando sobras de $10 \%$ sendo ajustado em dias alternados. A água era oferecida à vontade, fornecida em recipiente de volume conhecido, renovada uma vez ao dia.

Amostras de sangue foram coletadas por venopunção jugular, em tubos siliconizados à vácuo, sem anticoagulante para obtenção de soro e em tubos contendo anticoagulante de fluoreto de sódio para obtenção do plasma. A obtenção das amostras de urina foi feita por micção espontânea dos animais, utilizando-se bolsa plástica empregada em colonostomia (Mark Med) e foi aplicada na região prepucial por adesão com cola adesiva. Imediatamente após a micção, a urina centrifugada e aliquotada em tubos KMA, seguida de armazenamento a $-20^{\circ} \mathrm{C}$.

Os indicadores bioquímicos e minerais determinados tanto no sangue quanto na urina foram: Creatinina, ureia, ácido úrico, proteína total, glicose, cálcio, fósforo, magnésio, sódio, potássio e cloro. As determinações bioquímicas sanguíneas e urinárias foram realizadas em analisador bioquímico semiautomático (Bioplus Modelo BIO 2000), utilizando-se kit comercial (Doles).
Para determinação do Ca e Mg, as amostras foram submetidas à digestão nítrico-perclórica, e posteriormente determinados por meio de espectrômetro de absorção atômica (ICP-OES), utilizando-se aparelho modelo SpectrAA-200G. P foi determinado pelo método colorimétrico do molibidato de amônia, já o Na e K foram determinados por fotometria de chama, utilizando-se aparelho Micronal.

A ingestão de água foi mensurada mediante o cálculo da diferença entre a quantidade de água ofertada e sua sobra, descontando-se, ainda, a água perdida por evaporação. Para obtenção das perdas de água por evaporação foram utilizados baldes com a mesma quantidade de água ofertada aos animais, distribuídos no galpão experimental. Por diferença de peso em vinte e quatro horas, quantificou-se a perda média de evaporação.

A determinação dos índices urinários de alguns metabólitos e macroelementos foram obtidos por meio de fórmulas descritas por Garry et al. (1990). Determinou-se, portanto, índice de excreção urinária de $Y$ substância e taxa de excreção fracional de $Y$ substâncias, tais como: uréia, ácido úrico, proteína total, glicose, $\mathrm{Ca}, \mathrm{P}$, $\mathrm{Mg}, \mathrm{Na}, \mathrm{K}$ e $\mathrm{Cl}$. Para a determinação dos respectivos índices, as análises dos metabólitos e macroelementos ( $Y$ substância) foram determinadas tanto no soro quanto na urina, conforme fórmulas: Taxa de Depuração Endógena de Creatinina: TDECr (ml/min/kg) $=[($ CrUr x Volume de Urina $/ \mathrm{CrSr})] / \mathrm{PV}(\mathrm{kg})$; Índice de Excreção Urinária de (y) Substância: $\operatorname{IEUr}_{\mathrm{Y}}(\mathrm{mMol} / \mathrm{L})=\left(\mathrm{Ur}_{\mathrm{Y}} / \mathrm{CrUr}\right) \times \mathrm{PV}^{0,75}$; Reabsorção de Água Livre de Eletrólitos: $\mathrm{T}^{\mathrm{e}} \mathrm{H}_{2} \mathrm{O}(\mathrm{ml} / \mathrm{h})=$ Volume de Urina x $(\mathrm{NaUr}+\mathrm{KUr} / \mathrm{NaSr}-1) \cdot \mathrm{Ur}_{\mathrm{Y}}=\mathrm{Y}$ substância determinada na Urina; $\mathrm{Sr}_{\mathrm{Y}}=\mathrm{Y}$ substância determinada no soro; $\mathrm{CrUr}=$ Creatinina urinária; $\mathrm{CrSr}=$ Creatinina sérica; $\mathrm{PV}=$ Peso vivo; $\mathrm{PV}^{0,75}=$ Peso metabólico; $\mathrm{NaUr}=$ Sódio urinário; $\mathrm{NaSr}$ = Sódio sérico; $\mathrm{KUr}$ = Potássio urinário. 0 peso vivo em kg foi modificado para peso metabólico $\left(\mathrm{PV}^{0,75}\right)$.

Os dados foram submetidos a análises de variância. Os dados foram analisados por meio do programa computacional Statistical Analysis System (SAS 2000), utilizando-se o procedimento GLM do SAS. Foi adotado o nível de significância $(p)$ de $5 \%$.

\section{RESULTADOS E DISCUSSÃO}

0 consumo de MS foi maior $(\mathrm{P}<0,0121)$ para os animais que receberam a dieta composta por feno de tifton+palma in natura em comparação aos que receberam a dieta composta por feno de tifton, cujas médias foram 1411 e 786g/ dia, respectivamente. Com exceção do tratamento feno não houve diferença estatística entre os demais tratamentos.

A palma forrageira é uma forragem que apresenta alta palatabilidade, principalmente a cultivar miúda, que tem se mostrado mais palatável do que espécies do gênero Opuntia (Santos et al. 1992), o que está associado ao elevado nível de carboidratos solúveis (Santos et al. 1992, Santos et al. 2001). Essa característica associada à alta digestibilidade da MS pode ter favorecido o consumo das rações contendo palma, seja na forma de farelo ou in natura, o que corrobora com Sirohi et al. (1997) e Ben Salem et al. (1996) verificaram aumento no consumo de MS em g/dia e em relação ao peso metabólico, à medida que se elevou o nível de participação da palma em ração para ovinos.

A ingestão voluntária de água pelos animais submetidos às dietas contendo feno de tifton+palma in natura e palma in natura foi menor $(\mathrm{P}<0,0001)$ em relação aos demais tratamentos (Quadro 2). Este comportamento deve-se à quantidade de água que a palma contém, uma vez que a mesma apresenta baixo teor de matéria seca $(9,2 \%)$, e, consequen- 
temente, alto teor de umidade. Desta forma, proporcionou a redução da ingestão de água direta pelos animais. Esses resultados corroboram com os encontrados por Abidi et al. (2009) e Costa et al. (2009) quando estudaram a inclusão da palma na dieta de pequenos ruminantes.

Vieira et al. (2008a) em experimento com níveis crescentes de palma forrageira na dieta de caprinos $(37,3$; 47,$3 ; 57,2 ; 67,0 ; 76,5 \%$ ), observaram que a ingestão de água de bebida decresceu linearmente em função do aumento de palma forrageira na dieta. Tegegne et al. (2007), trabalhando com ovinos na Etiópia, avaliou o consumo de água de ovinos alimentados com diferentes níveis de palma forrageira em substituição ao feno de gramíneas nativas $(0 ; 20 ; 40 ; 60 ; 80 \%)$ e observou efeito linear decrescente da inclusão de palma forrageira sobre o consumo de água. Em trabalhos utilizando palma forrageira, Ben Salem et al. (1996) observaram que o volume de água consumido por ovinos diminuiu de 2,4 L da dieta controle (sem palma) para 0,1 L quando o consumo de palma foi maior do que $300 \mathrm{~g}$ de MS/dia, o que leva a ressaltar a importância dessa forrageira como fonte de água via alimento.

0 tratamento feno de tifton proporcionou aos animais menor ingestão voluntária de água quando comparado aos tratamentos feno de tifton+farelo de palma e farelo de palma isoladamente. Diversos trabalhos têm evidenciado a influência da fibra sobre a ingestão de água, fato esse que pode ser explicado pelo aumento da ruminação e consequentemente maior fluxo de saliva, seguido da maior taxa de diluição, proporcionando menor ingestão de água pelo animal em dietas com maior percentual de fibra. Analisando a composição das dietas experimentais (Quadro 1) observa-se que o tratamento feno possui maior teor de FDN quando comparado às dietas feno de tifton+farelo de palma e farelo de palma, isoladamente. É importante ressaltar, que outros fatores podem estar relacionados com a ingestão voluntária de água como presença de oxalato e minerais que aumentam a excreção urinária e, consequentemente, a ingestão voluntaria de água.

A ingestão de água via alimento, expressa em L/dia (Quadro 2) foi significativamente $(\mathrm{P}<0,0001)$ maior quando as dietas continham palma in natura em sua composição em relação aos demais tratamentos. A ingestão de água via alimento, tornou-se expressiva nas dietas contendo palma forrageira in natura, obtendo-se valores médios de 6,07 e 6,99 L/dia para as dietas Feno de tifton+Palma in natura e Palma in natura, respectivamente. Em relação à ingestão total de água, observou-se que dietas com feno de tifton+palma in natura e palma in natura, isoladamente, proporcionaram valores de 7,06 e 7,56 L/dia respectivamente. A água total ingerida em um dia é dada pelo somatório da água de bebida e aquela contida no alimento.

A ingestão de água via alimento sofre influência direta

Quadro 1. Composição percentual e valor nutritivo dos ingredientes das dietas experimentais

\begin{tabular}{lccccc}
\hline Componentes (\% na MS) & \multicolumn{4}{c}{ Dietas } \\
\cline { 2 - 6 } & Feno Tifton & $\begin{array}{c}\text { Feno Tifton }+ \\
\text { Farelo de Palma }\end{array}$ & $\begin{array}{c}\text { Feno Tifton + } \\
\text { Palma In Natura }\end{array}$ & Farelo de Palma Palma In Natura \\
\hline Feno de Tifton & 75,5 & 37,75 & 37,75 & - \\
Palma forrageira & - & - & 37,12 & - & 74,23 \\
Farelo de palma & - & 37,12 & - & - \\
Farelo de soja & 23,0 & 23,0 & 23,0 & 23,0 \\
Ureia & 0,00 & 0,63 & 0,63 & 23,0 & 1,27 \\
Calcário & 1,0 & 1,0 & 1,0 & 1,27 & 1,0 \\
Sal mineral & 0,5 & 0,5 & 0,5 & 1,0 & 0,5 \\
Total (\%) & 100,0 & 100,0 & 100,0 & 0,5 & 100,0 \\
& & & Nutrientes & 100,0 & 12,95 \\
MS & 88,15 & 88,2 & 22,6 & 88,25 & 16,30 \\
PB & 16,40 & 16,30 & 16,30 & 16,30 & 67,10 \\
NDT & 60,40 & 63,75 & 63,75 & 67,10 & 26,95 \\
FDN & 62,10 & 44,55 & 44,55 & 26,95 & 52,90 \\
Carboidratos Não Fibrosos & 10,30 & 31,60 & 31,60 & 52,90 & 1,80 \\
Extrato Etéreo & 1,60 & 1,70 & 1,70 & 1,80 & 2,22 \\
Ca & 0,83 & 1,52 & 1,52 & 2,22 & 0,35 \\
P & 0,31 & 0,33 & 0,33 & 0,35 &
\end{tabular}

MS = Matéria Seca, PB = Proteína Bruta, NDT = Nutriente Digestível Total, FDN = Fibra em Detergente Neutro, Ca = Cálcio, $\mathrm{P}$ = Fósforo. 1 = Farelo de Palma, 2 = Palma in natura.

Quadro 2. Ingestão de matéria seca (MS) e água por ovinos recebendo rações à base de palma forrageira (Nopalea cochenillifera) in natura ou desidratada em substituição ao feno Tifton

\begin{tabular}{lccccccc}
\hline \multicolumn{1}{c}{ Variáveis } & \multicolumn{7}{c}{ Tratamentos } \\
\cline { 2 - 8 } & $\begin{array}{c}\text { Feno } \\
\text { Tifton }\end{array}$ & $\begin{array}{c}\text { Feno Tifton }+ \\
\text { Farelo de Palma }\end{array}$ & $\begin{array}{c}\text { Feno Tifton + } \\
\text { Palma In Natura }\end{array}$ & $\begin{array}{c}\text { Farelo de } \\
\text { Palma }\end{array}$ & $\begin{array}{c}\text { Palma } \\
\text { In Natura }\end{array}$ & EPM & P \\
\hline & & \multicolumn{7}{c}{ Ingestão de MS e Água } \\
Matéria seca (g/dia) & $786,0 \mathrm{~b}$ & $1071,0 \mathrm{ab}$ & $1411,0 \mathrm{a}$ & $1108,0 \mathrm{ab}$ & $1014,0 \mathrm{ab}$ & 0,064 & 0,0121 \\
Bebida (L/dia) & $2,47 \mathrm{~b}$ & $4,12 \mathrm{a}$ & $0,99 \mathrm{bc}$ & $5,23 \mathrm{a}$ & $0,57 \mathrm{c}$ & 0,44 & 0,0001 \\
Alimento (L/dia) & $0,03 \mathrm{~b}$ & $0,04 \mathrm{~b}$ & $6,07 \mathrm{a}$ & $0,06 \mathrm{~b}$ & $6,99 \mathrm{a}$ & 0,76 & 0,0001 \\
Total (L/dia) & $2,50 \mathrm{~b}$ & $4,17 \mathrm{~b}$ & $7,06 \mathrm{a}$ & $5,29 \mathrm{ab}$ & $7,56 \mathrm{a}$ & 0,52 & 0,0016
\end{tabular}

$\overline{\mathrm{ED}}=$ Energia Digestível; FDN $=$ Fibra em detergente neutro; $\mathrm{CNF}=$ Carboidratos não fibrosos. 
Quadro 3. Volume de urina de ovinos recebendo rações à base de palma forrageira (Nopalea cochenillifera) in natura ou desidratada em substituição ao feno Tifton

\begin{tabular}{lccccccc}
\hline \multirow{2}{*}{ Variáveis } & \multicolumn{7}{c}{ Tratamentos } \\
\cline { 2 - 7 } & $\begin{array}{c}\text { Feno } \\
\text { Tifton }\end{array}$ & $\begin{array}{c}\text { Feno Tifton }+ \\
\text { Farelo de Palma }\end{array}$ & $\begin{array}{c}\text { Feno Tifton }+ \\
\text { Palma In Natura }\end{array}$ & $\begin{array}{c}\text { Farelo } \\
\text { de Palma }\end{array}$ & $\begin{array}{c}\text { Palma } \\
\text { In Natura }\end{array}$ & EPM & P \\
\hline Volume Urinário & & & & & & \\
Volume (mL/dia) & $1191,7 \mathrm{c}$ & $1132,5 \mathrm{c}$ & $3127,3 \mathrm{~b}$ & $1661,8 \mathrm{c}$ & $4006,5 \mathrm{a}$ & 18,29 & 0,0001 \\
Volume (mL/min) & $0,83 \mathrm{c}$ & $0,79 \mathrm{c}$ & $2,17 \mathrm{~b}$ & $1,15 \mathrm{c}$ & $2,78 \mathrm{a}$ & 18,26 & 0,0001
\end{tabular}

Médias minúsculas na linha seguidas de letras distintas diferem estatisticamente pelo teste de Tukey $(\mathrm{P}<0,05)$.

Quadro 4. Perfil dos índices de excreção urinária de metabólitos e minerais, TDECr, $\mathrm{T}^{\mathrm{e}} \mathrm{H}_{2} \mathrm{O}$ de ovinos recebendo rações à base de palma forrageira (Nopalea cochenillifera) in natura ou farelada em substituição ao feno Tifton

\begin{tabular}{|c|c|c|c|c|c|c|c|}
\hline \multirow[t]{2}{*}{ Índices Urinários } & \multicolumn{7}{|c|}{ Tratamentos } \\
\hline & $\begin{array}{l}\text { Feno } \\
\text { Tifton }\end{array}$ & $\begin{array}{c}\text { Feno Tifton }+ \\
\text { Farelo de Palma }\end{array}$ & $\begin{array}{c}\text { Feno Tifton }+ \\
\text { Palma In Natura }\end{array}$ & $\begin{array}{c}\text { Farelo } \\
\text { de Palma }\end{array}$ & $\begin{array}{l}\text { Palma } \\
\text { In Natura }\end{array}$ & EPM & $\mathrm{P}$ \\
\hline & \multicolumn{7}{|c|}{ Índice de excreção urinária de metabólitos e minerais } \\
\hline IEUrUr (mmol/L) & $242,20 b$ & $282,10 b$ & $453,90 \mathrm{ab}$ & $409,80 \mathrm{ab}$ & $606,60 \mathrm{a}$ & 3,00 & 0,0500 \\
\hline IEUrAcUr (mmol/L) & $17,83 \mathrm{ab}$ & $29,87 a$ & $28,47 a$ & $27,49 a$ & $7,76 \mathrm{~b}$ & 5,15 & 0,0082 \\
\hline IEUPt (mmol/L) & 866,20 & 1123,70 & 1211,20 & 1186,60 & 1353,80 & 0,66 & 0,6316 \\
\hline IEUrC & 0,51 & & 0,63 & 0,57 & 0,55 & 0,25 & 0,9059 \\
\hline IEUrC & $1,80 \mathrm{~b}$ & $2,90 \mathrm{~b}$ & $2,14 \mathrm{~b}$ & $3,63 b$ & $6,24 a$ & 4,88 & 0,0001 \\
\hline IEUrl & 0,58 & 1,26 & 0,69 & 1,16 & 1,58 & 1,89 & 0,1654 \\
\hline IEUrN & $1,95 \mathrm{c}$ & $24,16 \mathrm{~b}$ & $9,66 \mathrm{bc}$ & $38,85 a$ & $15,80 \mathrm{bc}$ & 9,32 & 0,0005 \\
\hline IEUrN & $37,39 b$ & $56,39 b$ & $41,17 \mathrm{~b}$ & $98,89 a$ & $52,21 b$ & 2,90 & 0,0582 \\
\hline IEUrK & $366,10 b$ & $712,20 \mathrm{ab}$ & $1166,90 \mathrm{ab}$ & $637,90 \mathrm{ab}$ & $1222,8 \mathrm{a}$ & 5,33 & 0,0304 \\
\hline \multirow[t]{2}{*}{ IEUrCl (mmol/L) } & 419,20 & 466,60 & 528,5 & 672,20 & 323,10 & 2,64 & 0,0750 \\
\hline & \multicolumn{7}{|c|}{ Taxa de depuração endógena de creatinina } \\
\hline \multirow[t]{2}{*}{ TDECr (ml/min/Kg) } & $1,11 b$ & $0,96 b$ & $1,98 \mathrm{a}$ & $1,02 b$ & $1,36 \mathrm{~b}$ & 4,11 & 07 \\
\hline & \multicolumn{7}{|c|}{ Reabsorção de água livre de eletrólitos } \\
\hline $\mathrm{T}^{\mathrm{e}} \mathrm{H}_{2} \mathrm{O}(\mathrm{ml} / \mathrm{h})$ & $28,22 b$ & $38,49 b$ & $123,46 a$ & $35,20 b$ & $122,80 \mathrm{a}$ & 8,37 & 0,0011 \\
\hline
\end{tabular}

Médias minúsculas na linha seguidas de letras distintas diferem estatisticamente pelo teste de Tukey $(\mathrm{P}<0,05)$.

do teor de umidade assim como dos nutrientes presentes no alimento, desta forma devido ao alto teor de umidade da palma forrageira, as dietas feno de tifton+palma in natura e palma in natura isoladamente proporcionaram um incremento na ingestão de água pelos animais. Devido ao alto teor de umidade da palma forrageira a ingestão de água via alimento influenciou a ingestão total de água dos animais alimentados pelas dietas contendo a palma in natura. Além disso, de acordo com Cymbaluk (1989) a ingestão de água é definida através da matéria seca e energia ingerida. Sendo assim, o maior consumo de água proporcionado por estas dietas ocorreu devido ao alto teor de umidade da palma in natura.

É importante ressaltar que, embora as dietas feno de tifton+palma in natura e palma in natura isoladamente fornecessem água suficiente para atender a exigência de água dos animais, eles ingeriram voluntariamente água, demonstrando que não é somente o consumo de MS ou de energia que determinam a ingestão de água. Essa ingestão voluntária de água pode apontar um gasto maior de água no metabolismo destes animais, o que pode ser indicativo da presença de algum componente nas dietas a base de palma que aumente a utilização ou até excreção de água, desta forma, aumentado também à necessidade de ingestão.

Apesar da ingestão total de água ter sido menor quando comparada aos tratamentos a base de palma in natura, os animais que consumiram farelo de palma a ingestão de água total também ultrapassou a necessidade do ani- mal. Isto pode indicar que esta ingestão excedente pode não estar relacionada com a exigência de água e sim com substâncias presente no alimento, como oxalato e minerais que aumentam a excreção urinária e, consequentemente, a ingestão voluntaria de água. De acordo com Langhans et al. (1995) a ingestão de água em níveis satisfatório é indispensável a digestão dos alimentos, absorção, eliminação de frações não digestíveis, bem como dos produtos residuais.

Os animais que ingeriram dieta com palma in natu$r a$ produziram maior volume de urina $(4.006,5 \mathrm{~mL} /$ dia $)$ $(\mathrm{P}<0,0001)$ que aqueles que receberam dieta com feno de tifton+palma in natura $(3.127,3 \mathrm{~mL} / \mathrm{L})$; enquanto que o volume de urina dos animais dos demais grupos foi semelhante (Quadro 3).

A observação de maior volume urinário produzido pelas dietas contendo palma forrageira na forma in natura é esperada, uma vez que a excreção urinária é necessária para manter a homeostase entre a ingestão de água, tanto por ingestão voluntária quanto via alimentos, e a excreção de água pelo organismo (Vieira et al. 2008b). Ficou comprovado que quando havia incorporação da palma in natura na dieta, maior era o volume urinário, ao contrário do que ocorria quando se utilizava feno de palma na dieta, fato justificado pelo maior aporte hídrico no componente dietético, bem como pela ação de eletrólitos com efeito diurético, como no caso do K. A palma forrageira é rica em água (80 - 90\%) e se caracteriza por ser uma excelente fonte de água via alimento (Tegegne et al. 2007, Vieira et al. 2008b), 
fato este que justifica maior produção de urina quando animais recebem dietas contento palma in natura.

Gebremariam et al. (2006), Vieira et al. (2008a, 2008b), Tegegne et al. (2007) e Costa el al. (2009) observaram aumento na excreção urinária com aumento da proporção de palma na dieta, e tal fato é explicado por Reece (2004), que animais recebendo dietas contendo alimentos muito suculentos, ricos em água, pode reduzir a ingestão de água e excretar considerável volume de urina, como mecanismo de regulagem do volume de água do corpo. Desta forma, é possível afirmar que o elevado teor de água presente na palma forrageira torna-se uma alternativa importante para regiões semiáridas.

Está comprovado que caprinos alimentados com ração contendo mais de $30 \%$ de palma forrageira in natura podem deixar de ingerir água diretamente no bebedouro e excretar maior volume de urina (Araújo et al. 2004, Reece 2004). Neste experimento o percentual de palma forrageira in natura teve variação de 37,12 a 74,23, explicando o fato de se observar maior volume de urina com o maior percentual de palma in natura na dieta.

Andrade-Montemayor et al. (2011) relatando sobre alimentos alternativos para pequenos ruminantes em áreas de semi-árido, que maior volume de urina é observado em animais que ingerem dietas com palma miúda (1161,64 $\mathrm{ml} /$ dia $)$ e palma gigante $(1228,03 \mathrm{ml} / \mathrm{dia})$, diferentemente do que ocorre com dieta sem palma $(743,07 \mathrm{ml} /$ dia $)$.

A dieta composta de palma in natura propiciou maior IEUrUr $(606,60 \mathrm{mmol} / \mathrm{L})$ quando comparado com dietas compostas por feno de tifton $(242,20 \mathrm{mmol} / \mathrm{L})$ e feno de tifton + farelo de palma $(282,10 \mathrm{mmol} / \mathrm{L})$. Quanto ao IEUrAcUr, maiores índices foram observados nas dietas compostas por feno de tifton + farelo de palma $(29,87 \mathrm{mmol} / \mathrm{L})$, feno de tifton + palma in natura $(28,47 \mathrm{mmol} / \mathrm{L})$ e farelo de palma $(27,49 \mathrm{mmol} / \mathrm{L})$, quando comparado com dieta com palma in natura $(7,76 \mathrm{mmol} / \mathrm{L})$.

Maior IEUrCa e IEUrK foram observados nos animais que receberam dieta com palma in natura $(6,24 \mathrm{mmol} / \mathrm{L} \mathrm{e}$ $1222,8 \mathrm{mmol} / \mathrm{L}$ ), enquanto que as demais dietas propiciaram similar índice de excreção urinária. Quanto ao IEUrMg e IEUrNa, maior índice foi observado nos animais que receberam dieta com farelo de palma $(38,85 \mathrm{mmol} / \mathrm{L}$ e 98,89 $\mathrm{mmol} / \mathrm{L}$ ), em relação aos demais grupos.

Os maiores IEUrUr e IEUrAcUr devem-se, provavelmente, ao aumento do volume de urina formado com a ingestão de palma in natura, e este maior fluxo urinário aumentou a excreção destes derivados purínicos, diferentemente do que aconteceu com dietas contendo feno de tifton e feno + farelo de palma (Quadro 4).

Com relação à ureia, este metabólito reflete a concentração de amônia no ambiente ruminal, resultado do catabolismo da proteína pelos microrganismos do rúmen; e quanto maior a concentração de proteína degradável no rúmen, maior a transformação de amônia em ureia no fígado e, consequentemente, maior sua excreção (Vieira et al. 2008b, Soares et al. 2006). Devendo-se considerar, também, a influência do volume hídrico corpóreo que pode ser adquirido pela ingestão voluntária de água ou absorção de água via alimento, como no caso da palma in natura.
Quanto ao IEUrCa, este índice pode ter relação direta com o maior consumo de Ca pela dieta. Como citado por Alcade et al (1999) e Batista et al. (2003), a palma forrageira possui elevados teores de Ca, além de $\mathrm{K}$ e Mg.

0 aumento do IEUrK já era esperado devido a grande quantidade de $\mathrm{K}$ existente na palma forrageira (Batista et al. 2003), já que ao aumentar a ingestão de K aumenta também a secreção de aldosterona e, consequentemente, maior IEUrK. Já a relação existente entre a concentração do Na e K no palma, esta justifica o comportamento da excreção urinária, uma vez que o menor IEUrNa foi observado nos animais que receberam palma na condição in natura, devendo-se a menor concentração deste eletrólito na composição da palma, refletindo diretamente não só a concentração sanguínea, quanto a urinária.

O maior IEUrMg em animais alimentados com palma in natura + farelo de palma e farelo de palma como único volumoso tiveram o mesmo comportamento, em que este teve provavelmente maior percentual de absorção nestas dietas. Szentmihályi et al. (1998) reportou que Mg, bem como $\mathrm{K}$ presentes nas plantas têm efeito diurético, sendo estes naturalmente excretados em maior quantidade.

Maior TDECr foi observada nos animais que receberam dieta com feno de tifton + palma in natura $(1,98 \mathrm{ml} / \mathrm{min} /$ $\mathrm{kg}$ ) quando comparado com as demais dietas experimentais $(\mathrm{P}<0,0207)$. Já em relação à reabsorção de água livre de eletrólitos $\left(\mathrm{T}^{\mathrm{e}} \mathrm{H}_{2} \mathrm{O}\right)$, animais que receberam dietas com feno de tifton + palma in natura $(123,46 \mathrm{ml} / \mathrm{h})$ e apenas palma in natura $(122,80 \mathrm{ml} / \mathrm{h})$ tiveram maiores valores médios quando comparado com as demais dietas $(\mathrm{P}<0,0011)$.

A TDECr bem como a taxa de reabsorção hídrica livre de eletrólitos aumentou com o aumento do nível de palma na dieta, provavelmente devido à quantidade de água presente na palma forrageira. 0 conteúdo total de água do corpo é mantido relativamente constante ao longo do dia, sendo controlado pela ingestão de água e excreção de urina. Esse controle é necessário para manter a homeostase, uma vez que, se por qualquer razão grande quantidade de água for incorporada ao fluido extracelular, ela passará para dentro das células e poderá alterar o metabolismo celular (Reece 2004).

Segundo Rivas et al. (1997), existe uma tendência de ocorrer maior TDECr em resposta a expansão de volume corporal, fato ocorrido com a ingestão de palma in natura na dieta dos ovinos. Foi visto que a ingestão de água por estes animais foi menor, porém o volume de urina foi maior, bem como a ingestão total de água tendo esta expansão de volume oriundo da dieta. A expansão de volume após ingestão de palma in natura aumentou a diurese e a taxa de reabsorção hídrica livre de eletrólitos. A magnitude desta reabsorção foi provavelmente atenuada por mecanismos regulatórios em relação ao volume de fluido extracelular (Rivas et al. 1997).

Outro fato que pode ter contribuído com este resultado, é que os animais alimentados com as dietas à base de palma in natura ingeriam água via alimento. Desta forma a ingestão voluntária de água é reduzida e o animal não necessita ingerir grandes quantidades de água de uma única vez, o que pode dificultar os mecanismos de reabsorção de 
água no trato-gastrointestinal. Ao ingerir água via alimento os animais recebiam pequenas quantidades de água de forma contínua o que pode ter resultado na maior eficiência na reabsorção de água, a qual ocorre no intestino grosso.

\section{CONCLUSÕES}

A presença da palma forrageira (Nopalea cochenillifera) tanto na condição de farelo como in natura proporciona aumento do volume urinário sem alterar a função renal.

A utilização de dietas com palma forrageira influencia a ingestão de água pelos ovinos, reduzindo a necessidade de fornecimento de água para os animais, o que deve ser considerado como uma excelente estratégia alimentar onde esse nutriente torna-se limitado.

Agradecimentos.- Ao Conselho Nacional de Desenvolvimento Científico e Tecnológico (CNPq) pela concessão de bolsa de mestrado e pelo auxílio financeiro (Edital MCT/CNPq - Universal, Faixa B).

\section{REFERÊNCIAS}

Abidi S., Ben Salem H., Martín-García A.I. \& Molina-Alcaide E. 2009. Ruminal fermentation of spiny (Opuntia amyclae) and spineless (Opuntia ficus indica finermis) cactus cladodes and diets including cactus. Anim. Feed Sci. Technol. 149:333-340.

Alcade C.R., Ezequiel J.M.B., Lema A.C.F. \& Malheiros E.B. 1999. Perdas endógenas e coeficientes de absorção aparente e real do magnésio em caprinos. Revta Bras. Zootec. 28:1347-1357.

Andrade-Montemayor H.M., Cordova-Torresb A.V., García-Gascac T. \& Kawasd J.R. 2011. Alternative foods for small ruminants in semiarid zones, the case of Mesquite (Prosopis laevigata spp.) and Nopal (Opuntia spp.). Small Rum. Res. 98:83-92.

Araújo P.R.B., Ferreira M.A., Brasil L.H.A., Santos D.C., Lima R.M.B., Véras A.S.C., Santos M.V.F., Bispo S.V. \& Azevedo M. 2004. Substituição do milho por palma forrageira em dietas completas para vacas em lactação. Revta Bras. Zootec. 33:1850-1857.

Batista A.M.V., Mustafa A.F., Santos G.R.A., Carvalho F.F.R., Dubeux J.C., Lira M.A. \& Barbosa S.B.P. 2003. Chemical composition and ruminal dry matter and crude protein degradability of spineless cactus. J. Agron. Crop Sci. 189:123-126.

Ben Salem H., Nefzaoui A., Abdouli H. \& Orskov E.R. 1996. Effect of increasing level of spineless cactus (Opuntia ficus indica var. inermes) on intake and digestion by sheep given strawbased diets. Anim. Sci. 62: 293-299.

Bispo S.V., Ferreira M.A., Véras A.S.C., Batista A.M.V., Pessoa R.A.S. \& Bleuel M.P. 2007. Palma forrageira em substituição ao feno de capim-elefante. Efeito sobre consumo, digestibilidade e características de fermentação ruminal em ovinos. Revta Bras. Zootec. 36:1902-1909.

Costa R.G., Beltrão Filho E.M., Medeiros A.N., Givisiez P.E.N., Queiroga R.C.R.E. \& Melo A.A.S. 2009. Effects of increasing level of cactus pear (Opuntia ficus indica L. Miller) in the diet of dairy goats and its contribution as a source of water. Small Rum. Res. 82:62-65.

Cymbaluk N.F. 1989. Water balance of horses fed various diets. Equine Pract. 11:19-24.

Garry F., Chew D.J., Rings D.M., Tarr M.J. \& Hoffsis G.F. 1990. Renal excre- tion of creatinine, electrolytes, protein, and enzymes in healthy sheep. Am. J. Vet. Res. 51:414-419.

Gebremariam T., Melaku S. \& Yami A. 2006. Effect of different levels of cactus (Opuntia ficus indica) inclusion on feed intake, digestibility and body weight gain in tef (Eragrostis tef) straw-based feeding of sheep. Anim. Feed Sci. Technol. 31:42-51.

Germano R.H., Barbosa H.P., Costa R.G., Medeiros A.N. \& Carvalho F.F.R. 1999. Avaliação da composição química e mineral de seis cactáceas do semi-árido paraibano. Agropec. Téc. 20:51-57.

Langhans W., Rossi R. \& Scharrer E. 1995. Relationships between feed and water intake in ruminants, p.199-216. In: Englehardt W.V., Leonhard-Marek S., Breves G. \& Geisecke D. (Eds), Ruminant Physiology: digestion, metabolism, growth and reproduction. Ferdinand Enke Verlag, Stuttgart, Germany.

McDowell R.L. 1996. Feeding minerals to cattle on pasture. Anim. Feed Sci. Technol. 60:247-271.

Reece W.O. 2004. Dukes' Physiology of Domestic Animals. 12th ed. Cornell University Press, Ithaca. 999p.

Rivas L.J., Hinchcliff K.W., Koh N.C.W., Sams R.A. \& Chew D.J. 1997. Effect of sodium bicarbonate administration on renal function of horses. Am. J. Vet. Res. 58:664-671.

Santos M.V.F., Lira M.A., Farias I., Hélio A., Burity H.A. \& Tavares Filho J.J. 1992. Efeito do período de armazenamento pós- colheita sobre a matéria seca e composição química das palmas forrageiras. Pesq. Bras. Agropec. 27:777-783.

Santos D.C., Santos M.V.F., Farias I., Dias F.M. \& Lira M.A. 2001. Desempenho produtivo de vacas $5 / 8$ Holando/Zebu alimentadas com diferentes cultivares de palma forrageira (Opuntia e Nopalea). Revta Bras. Zootec. 30:12-17.

Silva D.J. \& Queiroz A.C. 2002. Análise de Alimentos: métodos químicos e biológicos. 3a ed. Imprensa Universitária, Viçosa. 235p.

Sirohi S.K., Karim S.A. \& Misra A.K. 1997. Nutrient intake and utilization in sheep fed with prickly pear cactus. J. Arid Environ. 36:161-166.

Soares P.C., Maruta C.A., Sucupira M.C., Mori C.S., Kitamura S.S., Antonelli A.C. \& Ortolani E.L. 2006. Diagnóstico de carência energética em bovinos por testes de metabolismo ruminal. Braz. J. Vet. Res. Anim. Sci. 43:33-41.

SAS 2000. SAS User's Guide: statics version. Statistical Analysis Sistem Institute, Inc., Cary, NC.

Szentmihályi K., Kéry A., Then M.B., Lakatos B., Sándor Z. \& Vimkler P. 1998. Potassium-sodium ratio for the characterization of medicinal plant extracts with diuretic activity. Phytoth. Res. 12:163-166.

Tegegne F., Kijora C. \& Peters K.J. 2007. Study on the optimal level of cactus pear (Opuntia ficus indica) supplementation to sheep and its contribution as source of water. Small Rum. Res. 72:157-164.

Van Soest P.J., Robertson J.B. \& Lewis B.A. 1991. Methods for dietary fiber, neutral detergent fiber and nonstarch polysacharides in relation to animal nutrition. J. Dairy Sci. 74:3586-3597.

Vieira E.L., Batista A.M.V., Guim A., Carvalho F.F., Nascimento A.C., Araújo R.F.S. \& Mustafa A. 2008a. Effects of hay inclusion on intake, in vivo nutrient utilization and ruminal fermentation of goats fed spineless cactus (Opuntia ficus indica Mill) based diets. Anim. Feed Sci. Technol. 141:199208.

Vieira E.L., Batista A.M.V., Mustafa A.F., Araújo R.F.S., Soares P.C., Ortolani E.L. \& Mori C.S. 2008b. Effects of feeding high levels of cactus (Opuntia ficus indica Mill) cladodes on urinary output and electrolyte excretion in goats. Livest. Sci. 114:354-57. 